\title{
Variação de pH e do comprimento de sarcômero em músculos de búfalos (Bubalus bubalis var. bubalis) durante a obtenção de carcaças resfriadas
}

\section{$\mathrm{PH}$ and sarcomere length variation of buffalo (Bubalus bubalis var. bubalis) muscles during carcass chilling}

\author{
Fernando Elias Rodrigues da Silva, ${ }^{\star}$ Teófilo José Pimentel da Silva, ${ }^{\star \star}$ José de Arimatéia Freitas,

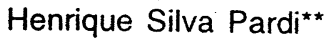

\begin{abstract}
Resumo
Com o objetivo de estudar as características do rigor mortis em carcaças frigorificadas de búfalos (Bubalus bubalis var bubalis) para consumo em Belém-PA, estudou-se o pH e o comprimento de sarcômero dos músculos bíceps braquial e grácil. Trabalhou-se com 10 animais abatidos em matadouro frigorífico sob normas do Serviço de Inspeção Federal, realizando-se as seguintes análises: medidas de temperatura da carcaça, pH e comprimento de sarcômero. As análises foram efetuadas na $1^{\mathrm{a}}, 5^{\mathrm{a}}, 10^{\mathrm{a}}, 12^{\mathrm{a}}, 15^{\mathrm{a}}$ e $24^{\mathrm{a}}$ horas após o abate, sendo as carcaças estocadas em câmara frigorífica mantida à temperatura de $3^{\circ} \mathrm{C}$ $\pm 1^{\circ} \mathrm{C}$. Os valores médios de $\mathrm{pH}$ obtidos nos diferentes tempos após o abate, para os músculos bíceps braquial e grácil, foram to de sarcômero foram: 1,$92 ; 167 ; 1,46 ; 1,47 ; 1,61 ; 1$ e 6,$85 ; 6,48 ; 6,31 ; 6,27 ; 6,17 ; 6,10$; e da mesma forma para o comprimenticos conclui-se ticos conclui-se que não existe diferença significativa $(\mathrm{p}>0,01)$ entre os valores médios de $\mathrm{pH}$ para os músculos bíceps

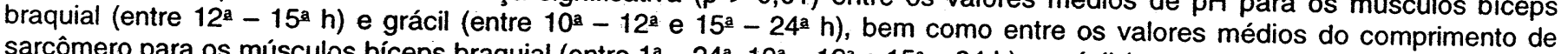
sarcômero para os músculos bíceps braquial (entre $1^{\mathrm{a}}-24^{\mathrm{a}}, 10^{\mathrm{a}}-12^{\mathrm{a}}$ e $15^{\mathrm{a}}-24 \mathrm{~h}$ ) e grácil (entre $10^{\mathrm{a}}-12^{\mathrm{a}}$ e $15^{\mathrm{a}} \mathrm{h}$ ). Observouse uma correlação linear inversa entre tempo após o abate e comprimento de sarcômero desses músculos $(r=-0,0564$ e carcaça e comprimento de sarcômero $(r=0,4372$ rimento de sarcômero $(r=0,2537$ e 0,3075$)$ e média entre temperatura da bíceps braquial e na $12^{\text {a }}$ hora para o grácil.
\end{abstract}

Palavras-chave: búfalo; carcaça; frigorificação; rigor mortis; $\mathrm{pH}$; comprimento de sarcômero.

\begin{abstract}
In order to study rigor mortis features in chilling carcasses of buffaloes (Bubalis bubalis var. bubalis) for human consumption in Belém (State of Pará, Brazil), $\mathrm{pH}$ and sarcomere length of biceps brachil and gracilis muscles were studied. Ten animals slaughtered in an abbatoir under Federal Inspection were used for the following analyses: carcass temperature, $\mathrm{pH}$, and in chill room kept at $3^{\circ} \mathrm{C} \pm 1^{\circ} \mathrm{C}$. $\mathrm{pH}$ mean values obtained at 12,15 and 24 hours after slaughter. The carcasses were stored muscles were: $6.80,6.45,6.22,6.17$ mean values obtained at the different times after slaughter for biceps brachii and gracilis micra): $1.92,1.67,1.46,1.47,1.61,1.06,6.01$ and $6.85,6.48,6.31,6.27,6.17,6.10$, respectively. Sarcomere lengths were (in differences were observed ( $p>0.01$ ) between $\mathrm{pH}$ ( (from $15^{\text {th }}$ to $24^{\text {th }}$ hour). Mean values of saros brachii (from $12^{\text {th }}$ to $15^{\text {th }}$ hour) and gracilis to $24^{\text {th }}$ hour) and gracilis muscle (from $10^{\text {th }}$ to $12^{\text {th }}$ hour and at $15^{\text {th }}$ hour) showed (from $1^{\text {st }}$ to $24^{\text {th }}$ hour, $10^{\text {th }}$ to $12^{\text {th }}$ hour and $15^{\text {th }}$ inverse linear correlation between time between carcass temperature and sarcomere length $(r=0.4372$ sand lenght $(r=-0.0564$ and -0.1057$)$ and a mean correlation length ( $r=0.2537$ and 0.3075$)$ was observed. Maximum the $12^{\text {th }}$ hour with gracilis muscle.
\end{abstract}

Keywords. buffalo; carcass; chilling; rigor mortis; $\mathrm{pH}$; sarcomere lenght.

- Faculdade de Ciências Agrárias do Pará - Belém, PA

* Departamento de Tecnologia dos Alimentos - Faculdade de Veterinária - UFF - CEP 24230-340 - Niterói - RJ, e-mail: tjpsilva@bol.com.br 


\section{Introdução}

Os bubalinos são animais da espécie Bubalus bubalis, sendo que a variedade bubalis compreende as raças Murrah, Jafarabadi e Mediterrâneo. O búfalo foi introduzido, no Brasil, no final do século passado, na liha de Marajó, estado do Pará, ocorrendo uma grande adaptação desses animais ao ambiente amazônico, sendo a região Norte o maior reduto populacional ( $50 \%$ ) do efetivo total de mais de 2 milhões de cabeças desta espécie (Ramos, 1990). A carne bubalina é muito semelhante à carne bovina, em composição química e valor nutritivo (Nascimento e Moura, 1993).

Os parâmetros utilizados para a determinação do $\mathrm{pH}$ da carne de búfalo são aqueles atualmente estabelecidos para bovinos. De modo semelhante, o conhecimento a respeito das características do rigor mortis de carcaças de búfalos, tem como modelo o fenômeno observado em bovinos. Músculos braquiocefálico e psoas maior de 5 bovinos e de 5 búfalos, com as mesmas características e idade, resultaram na primeira hora após o abate em pH 6,3 e 5,8 para os músculos dos bovinos e em 5,9 e 5,5 para os búfalos (Moreno et al., 1994).

Estudo sobre o efeito do $\mathrm{pH}$ e da temperatura post mortem na estrutura e maciez do músculo longo dorsal de búfalos, demonstrou que os músculos com pH inicial mais elevado $(6,03)$ resultaram em sarcômeros mais longos $(1,92 \mu \mathrm{m})$, fibras de diametro menor $(62,64 \mu \mathrm{m})$ e maior maciez em comparacão com os de pH inicial mais baixo (Dushyanthan et al., 1994). Amostras do músculo longodorsal de búfalos, estocados à temperatura de $0-4^{\circ} \mathrm{C}$ e analisados após 2 horas, 2 e 12 dias, mostraram que o valor de $\mathrm{pH}$ dos músculos foi marcadamente afetado pelo esforço dos animais antes do abate (EI -Koussy et al., 1977). Além disso, com o intuito de comparar algumas propriedades da carne de bovinos e bubalinos, foi demonstrado que os músculos de búfalos foram mais escuros, ainda que os valores finais de $\mathrm{pH}$ não diferissem; o saboroma, a aceitabilidade e a suculência da carne de búfalos foi estatisticamente menor, enquanto que a força de cizalhamento ou dureza foi maior (Robertson et al., 1983).

Por outro lado, não se conhece ainda a correlação de pH e do comprimento de sarcômero em músculos de búfalos durante o processamento industrial para obtenção de carcaças resfriadas, nas condições brasileiras de produção. Assim, o objetivo deste trabalho foi estudar o comportamento do rigor mortis nos músculos bíceps braquial e grácil, em carcaças de búfalos, mediante a determinação do valor da temperatura, de $\mathrm{pH}$ e do comprimento de sarcômero, durante o processamento industrial de frigorificação, e estabelecer a correlação entre esses valores.

\section{Material e métodos}

Foram empregados no experimento 10 animais bubalinos mestiços, sendo 8 machos inteiros e 2 fêmeas, com idade variando entre 2 e 3 anos, oriundos de criatórios em regime extensivo de fazendas localizadas na ilha do Marajó - PA. Após receberem os cuidados ante-mortem de descanso, jejum e dieta hídrica durante 24 horas nos currais, foram submetidos à inspeção ante-mortem e abatidos sob normas do Serviço de Inspềção Federal (SIF $n^{\circ} 903$ ), no matadouro frigorífico do Tapaña - Belém - PA. O hábito reduzido de consumo de carne resfriada fez com que dispusemos apenas de duas carcaças resfriadas por semana, para atender exclusivamente a este estudo. Após a pesagem e a lavagem, as meias carcaças foram destinadas para a câmara de resfriamento, onde permaneceram por 24 horas à temperatura de $3^{\circ} \mathrm{C} \pm 1^{\circ} \mathrm{C}$.

$\mathrm{O}$ experimento compreendeu a tomada de temperatura da massa muscular, da medida do $\mathrm{pH}$ e da determinação do comprimento de sarcômero da carcaça de 10 búfalos, na $1{ }^{a}$, $5^{\mathrm{a}}, 10^{\mathrm{a}}, 12^{\mathrm{a}}, 15^{\mathrm{a}}$ e $24^{\mathrm{a}}$ hora após o abate.

Mediu-se a temperatura introduzindo a haste metálica do termômetro de incisão (marca Taylor), com escala variando entre $+55^{\circ} \mathrm{C}$ a $-45^{\circ} \mathrm{C}$ até uma profundidade de $3 \mathrm{~cm}$ da massa muscular do glúteobíceps. A medida do $\mathrm{pH}$ foi realizada nos músculos bíceps braquial e grácil, fazendo uma incisão com um bisturi e introduzindo o eletrodo do potenciômetro (marca Micronal) até uma profundidade de 1 $\mathrm{cm}$. Antes de cada medida do $\mathrm{pH}$, fez-se a calibração do eletrodo $(\mathrm{pH} \mathrm{4,0} \mathrm{e} \mathrm{pH} \mathrm{7,0).} \mathrm{De} \mathrm{cada} 1 / 2$ carcaça foi colhida uma amostra $(0,5 \times 1,0 \times 0,5 \mathrm{~cm})$ por tempo após o abate de cada músculo (bíceps braquial e grácil), perfazendo 20 amostras. Estas 20 amostras foram fixadas em liquido de Bouin, lavadas em água destilada, clivadas $(1 \times 0,2 \times 0,5 \mathrm{~cm})$, desidratadas, clarificadas, embebidas em parafina, emblocadas, microtomadas para 5 micra (Micrótomo marca Pika Seiko), distendida em banho-maria histológico (marca Fabre), transferida para lâmina de vidro, secadas, desparafinizadas, histratadas, oxidadas, lavadas, coradas com hematoxilina fosfotungstica de Mallory, desidratadas, clarificadas e montadas em lâmina com bálsamo do Canadá, de acordo com a metodologia de Behmer et al. (1976). A mensuração dos sarcômeros foi realizada no Laboratório do Departamento de Tecnologia de Alimentos da UFF, com um microscópio óptico marca Nikon Alphaphot VS, empregando-se uma ocular milimetrada e objetiva de inversão. Contava-se a quantidade de sarcômeros existentes no espaço de 10 micrômetros de uma miofibrila de seis diferentes campos, obtendo-se um valor médio. A média era multiplicada pelo fator de correção para a objetiva de inversão (igual a 1) e o valor expresso em micrômetros $(\mu \mathrm{m})$, seguindo a técnica de Sloss e Kemp (1978).

O tratamento estatístico compreendeu análise de regressão para estabelecer o modelo matemático que melhor interpretasse as variáveis em estudo; os coeficientes de correlação linear de Pearson; e a análise de variância para comparar os valores médios das variáveis. Para isso, utilizou-se o programa estatístico SAEG (Sistema para Análises Estatísticas e Genéticas).

\section{Resultados e discussão}

A queda dos valores de $\mathrm{pH}$ dos músculos após o abate constitui um fator marcante na conversão de músculo para carne, e ocorre em concomitância com a instalação do rigor mortis. Assim, os valores médios de $\mathrm{pH}$ inicial (logo após a sangria) obtidos neste estudo foram de $6,80 \pm 0,15$ para o músculo bíceps braquial e de $6,85 \pm 0,16$ para o grácil, conforme mostra a Tabela 1. 
Tabela 1: Valores médios de $\mathrm{pH}$ dos músculos bíceps braquial e grácil, das carcaças de búfalos mantidos à temperatura de $3^{\circ} \mathrm{C} \pm 1^{\circ} \mathrm{C}$, em função do tempo após o abate.

\begin{tabular}{|c|c|c|c|c|c|c|c|}
\hline \multirow[t]{2}{*}{ Amostras } & \multirow[b]{2}{*}{ n } & \multicolumn{6}{|c|}{ Valores $\mathrm{pH}(\mathrm{x} \pm \mathrm{s})^{1} / \mathrm{Tempo}(\mathrm{h})$ após o abate } \\
\hline & & 01 & 05 & 10 & 12 & 15 & $24 \mathrm{~h}$ \\
\hline \multirow[t]{2}{*}{ Bíceps Braquial } & 10 & $6,80^{\mathrm{a} 2}$ & $6,45^{b}$ & $6,22^{c}$ & $6,17^{\text {cd }}$ & $6,06^{\text {dd }}$ & $6,01^{\mathrm{d}}$ \\
\hline & & $(0,15)$ & $(0,18)$ & $(0,15)$ & $(0,16)$ & $(0,15)$ & $(0,17)$ \\
\hline \multirow[t]{2}{*}{ Grácil } & 10 & $6.85^{\mathrm{a}}$ & $6,48^{b}$ & $6,31^{\mathrm{bc}}$ & $6,27^{\mathrm{bc}}$ & $6,17^{\mathrm{c}}$ & $6,10^{\mathrm{c}}$ \\
\hline & & $(0,16)$ & $(0,21)$ & $(0,21)$ & $(0,21)$ & $(0,22)$ & $(0,20)$ \\
\hline
\end{tabular}

' $x$ : média; s: desvio-padrão

2 Médias seguidas por letras distintas, na linha, diferem entre si pelo Teste de Duncan $(p<0,01)$

Estes resultados concordam com os estudos de Dushyanthan et al. (1994), que encontraram para um grupo de búfalos, valores altos de $\mathrm{pH}$ inicial, que variavam de 6,60 a 6,79 , intermédio $(6,40$ a 6,59$)$ e baixo $(6,20$ a 6,39$)$ do músculo longo dorsal. Por outro lado, os outros autores encontraram valores médios de $\mathrm{pH}$, duas horas após o abate (de búfalos) de 5,60 a 5,73 , e atribuíram estes baixos valores ao estresse sofrido pelos animais no momento do abate (El-Koussy et al., 1977) e de 5,9 e 5,5 na primeira hora após o abate dos búfalos. Isso também se deu, provavelmente devido ao estresse desses animais (Moreno et al., 1974).

Os valores de $\mathrm{pH}$ final, 24 horas após o abate, 6,01 $\pm 0,17 \mathrm{e}$ $6,10 \pm 0,20$ (Tabela 1) estão de acordo com os obtidos pelos outros autores como Dushyanthan et al. (1994), que foi de 6,09 no final do primeiro dia de estocagem do músculo longo dorsal de búfalos, quando estocados a $4^{\circ} \mathrm{C}$. No entanto, discordam dos resultados de outros autores, como: 5,$43 ; 5,40$; 5,37 , quando estocado a $0-4^{\circ} \mathrm{C}$ após dois dias do abate (E)Koussy et al., 1977); de 5,8; 5,6; 5,7 após 24 horas do abate (Felício et al., 1979) de 5,$57 ; 5,57 ; 5,70 ; 5,65$ a $0-2^{\circ} \mathrm{C} / 48 \mathrm{~h}$ (Robertson et al., 1983). A temperatura média das carcaças foi de $8,9^{\circ} \mathrm{C} \pm 3,03^{\circ} \mathrm{C}$ nas primeiras 10 horas de resfriamento, quando deveria ser de $\sim 15^{\circ} \mathrm{C}$. Assim, os valores de $\mathrm{pH} 6,01$ e 6,10 ao final de 24 horas foi provavelmente em função do retardamento da glicólise anaeróbica. Isso pode ter ocorrido devido ao pequeno número de carcaças (2), para a grande dimensão da câmara de resfriamento $(6 \times 12 \times 4,5 \mathrm{~m})$, e da ausência de gordura de cobertura nessas carcaças.

O desenvolvimento do rigor mortis ocorre imediatamente após a morte, sendo caracterizado por um processo de encurtamento dos músculos (rigidez e inextensibilidade), e pela resolução desse rigor, diminuindo esse grau de encurtamento,

\section{Referências}

BEHMER,O.A., TOLOSA, E.M.C., NETO, A.G.F. Manual de técnicas para histologia normal e patológica. São Paulo: Editora da Universidade de São Paulo, 1976.239 p.

DUSHYANTHAN, K., KOSALARAMAN, V.R., RADAKRISHNAN, K.T. Effect of post mortem $\mathrm{pH}$ and temperature on buffalo Longissimus dorsimuscle structure and tenderness. Indian Veterinary Journal, v. 71, p. 791-794, 1994. e, por conseguinte, melhorando a maciez da carne.

Assim, os valores médios de comprimento de sarcômeros obtidos uma hora e 24 horas após o abate foram: $1,92 \mu \mathrm{m}$ e $1,82 \mu \mathrm{m}$ (biceps braquial) e $1,88 \mathrm{im}$ e $1,84 \mu \mathrm{m}$ (gracil), conforme mostra a Tabela 2.

Tabela 2: Valores médios do comprimento de sarcômeros $(\mu \mathrm{m})$ dos músculos bíceps braquial e grácil, das carcaças de búfalos mantidos à temperatura de $3^{\circ} \mathrm{C} \pm 1^{\circ} \mathrm{C}$, em função do tempo após o abate.

\begin{tabular}{|c|c|c|c|c|c|c|c|}
\hline \multirow[t]{2}{*}{ Amostras } & \multicolumn{7}{|c|}{ Comprimento sarcômero, $\mu \mathrm{m}^{\prime}(\mathrm{x} \pm \mathrm{s}) / \mathrm{Tempo}(\mathrm{h})$ após o abate } \\
\hline & n & 01 & 05 & 10 & 12 & 15 & $24 \mathrm{~h}$ \\
\hline \multirow[t]{2}{*}{ Bíceps Braquial } & 10 & $1.92^{\mathrm{a} 2}$ & $1,67^{\mathrm{ab}}$ & $1,46^{\mathrm{b}}$ & $1.47^{\mathrm{h}}$ & $1.61^{\mathrm{ab}}$ & $1.82^{\mathrm{a}}$ \\
\hline & & $(0,14)$ & $(0,15)$ & $(0,14)$ & $(0.13)$ & $(0.31)$ & $(0,40)$ \\
\hline \multirow[t]{2}{*}{ Grácil } & 10 & $1,88^{\mathrm{a}}$ & $1,71^{\mathrm{b}}$ & $1.57^{\mathrm{c}}$ & $1.46^{\mathrm{c}}$ & $1.49^{\mathrm{c}}$ & $1,84^{\mathrm{ab}}$ \\
\hline & & $(0,10)$ & $(0,10)$ & $(0,08)$ & $(0,11)$ & $(0,07)$ & $(0,19)$ \\
\hline
\end{tabular}

1 1 m: micrômetro; $x$ : média ; s: desvio-padrāo

${ }^{2}$ Médias seguidas por letras distintas, na linha, diferem entre si pelo Teste de Duncan $(p<0,01)$.

Estes resultados estão de acordo com os descritos por outros autores que encontraram valores médios para o músculo longo dorsal de búfalos de $1,84 \mu \mathrm{m}$ no início do post-mortem, e de $1,87 \mu \mathrm{m}$ apos 48 horas (Dushyanthan et al., 1994) quando estocado a $4^{\circ} \mathrm{C}$; e de 1,81 após 48 horas (Robertson et al., 1983). A menor média encontrada para o comprimento de sarcômeros foi de $1,46 \mu \mathrm{m} \pm 0,15$ para o músculo bíceps braquial na $10^{\mathrm{a}}$ hora após $\circ$ abate, e de $1,46 \mu \mathrm{m} \pm 0,11$ para 0 músculo grácil na $12^{\mathrm{a}}$ hora, correspondendo ao momento de instalação do rigor mortis. Não foi encontrado trabalho similar na literatura pesquisada. No entanto, para bovinos, os valores mínimos encontrados foram de 1,69 e $1,35 \mu \mathrm{m}$ na $15^{\mathrm{a}}$ hora após 0 abate para os respectivos músculos.

\section{Conclusões}

Após os testes estatísticos, conclui-se que não existe diferença significativa $(p>0,01)$ entre os valores de $\mathrm{pH}$ para os músculos bíceps braquial (entre $12^{\mathrm{a}}-15^{\mathrm{a}}$ hora) e grácil (entre $10^{a}-12^{a}$ e $15^{a}-24^{a}$ hora); observou-se uma correlação linear inversa entre o tempo após o abate e comprimento de sarcômero desses músculos $(r=-0,0564$ e $-0,1057$, respectivamente), fraca entre $\mathrm{pH}$ e comprimento de sarcômero $(r$ $=0,2537$ e 0,3075) e média entre temperatura da carcaça e comprimento de sarcômero $(r=0,4372$ e 0,4921$)$. O ponto de máxima contração ocorreu na $10^{\mathrm{a}}$ hora para o bíceps braquial e na $12^{\mathrm{a}}$ hora para o grácil.

EL-KOUSSY, H.A, AFIFT, Y.A, DESSOURI, T.I., EL-ASHRY, M.A. Some chemical and physical changes of buffalo meat after slaughter. Agricultural Research Review, v. 55, p. 1-7, 1977.

FELÍCIO, P.E., PICCHI, V., CORTE, O.O. Composição corporal, composição da carcaça e qualidade de carne de búfalos Jafarabadi. Boletim Técnico CTC-ITAL, n. 4, p. 1-43, 1979.

MORENO, A.G., RICETTI, R.V., PANETTA, J.C. Comportamento do pH dos músculos braquiocefálico e psoas major de bovinos (Bost taurus) e búfa- 
Ios (Bubalus bubalis) recém-abatidos. CONGRESSO BRASILEIRO DE MEDICINA VETERINÁRIA, 14., 1974, São Paulo. Anais, 1974.p. 167.

NASCIMENTO, C., MOURA CARVALHO, L.O. Criação de búfalos: alimentação, manejo, melhoramento e instalações. Brasília, DF: EMBRAPA - SPI, 1993. 403p.

RAMOS, A. A. Resultados V Torneio Leiteiro de Búfalos do Brasil Central: 1990. Botucatu: FMVZ/UNESP, 1990.13p.
ROBERTTSON, J., BOUTON, P.E., HARRIS, W.R., SHORTHOSE, W.R., RATCLIFF,D. A comparision of some properties of beef and buffalo (Bubalus bubalis) meat. Journal of Food Science, v. 48, p. 686-694, 1983.

SLOSS, M.W.B.S., KEMP, R.L.A.B. Veterinary Clinical Parasitology. 5. ed. Ames: lowa State University Press, 1978. p. 247. 